\title{
Perception of Informed Consent among Private Dental Practitioners of Bangalore South - A Kap Study
}

\author{
Ankita Gupta ${ }^{1 *}$ and Abhishek Purohit ${ }^{2}$ \\ ${ }^{1}$ Department of Public Health Dentistry, Dayananda Sagar College of Dental Sciences, India \\ ${ }^{2}$ Department of Public Health Dentistry, Peoples College of Dental Sciences, India
}

Received: January 02, 2018; Published: January 12, 2018

*Corresponding author: Ankita Gupta, Department of Public Health Dentistry, Dayananda Sagar College of Dental Sciences, Bangalore, Tel: 7000415924; Email: ankita26gupta88@gmail.com

\section{Abstract}

Aim: A cross sectional study was conducted to explore the knowledge, attitude and perceived implications of ethics of informed consent among dental surgeons of Bangalore South.

Materials and Methods: The study was conducted among 205 dental practitioners of Bangalore South. Questionnaire consisting of 27 questions was used for this purpose and was distributed to the practitioners.

Results: Among 205 dental practitioners, $60.5 \%$ were males and $39.5 \%$ were females. Based on education level of dentists, they were classified as: BDS (55.1\%) and MDS (44.9\%). Majority of the dentists (91\%) were aware about informed consent and $89.7 \%$ of them agreed that it was necessary to explain treatment plan before taking consent. Ninety three (45\%) dentists responded that they obtained the oral form of informed consent. Almost all participants $(187 ; 91 \%)$ reported that they should always take informed consent when they treated children.

Conclusion: The present study revealed that majority of the participating dentists was aware of their duty and obligation towards the patients. Although, informed consent played a major role in the daily practice of the majority, many were not using written consent as a routine procedure.

Clinical significance: Despite its importance in medicine and dentistry, clinician ignores the value of taking proper informed consent from patients. Therefore there is an urgent need to give priority to this area by changing the attitude of the practitioners towards it

Keywords: Informed consent; Dental practice; Ethics; Malpractice; Patient right

Abbreviations: ICH-GCP: International Conference on Harmonization Guidelines for Good Clinical Practice; IDA: Indian Dental Association; AAP: American Academy of Paediatrics

\section{Introduction}

Informed consent is a crucial prerequisite for undertaking ethical research or conducting a healthcare intervention on a person. It acts as a bridge between a doctor and a patient in which each of them has their own rights and responsibilities [1]. According to the International Conference on Harmonization Guidelines for Good Clinical Practice (ICH-GCP) Guidelines, informed consent is defined as "a process by which a subject voluntarily confirms his or her willingness to participate in a particular trial, after having been informed of all aspects of the trial that are relevant to the subject's decision to participate [2]. The first foundation of medical ethics was laid at the Hippocrates school (400-300 BC) [3].

The ethical codes at that time were often assembled in the form of oaths but the most famous was the Oath of Hippocrates [4], which is still considered as sacred in the present time. In 1947 during the World War II, the Nazi doctors performed unethical and life threatening medical experiments on war prisoners including children without taking their permission. Later on, they were accused and this led to the initiation of taking informed consent in biomedical research, which was known as Nuremberg code of medical ethics [5]. In 1964, Declaration of Helsinki was formalized by World Medical Association which refined the rules and regulations concerning the informed consent process and stated the ethical principles for medical research involving human subjects. In dentistry, informed consent gained recognition in mid 1980s [6] and since then various elements and steps have been added to standardize informed consent [7]. In India, the Dental Council is concerned with maintaining rules and regulations among dental professionals known as code of ethics that specifies certain duties related with the welfare of patients [8]. 
A conventional consent has many forms. It can be implied, verbal or written. Implied consent can be seen in a situation when a new patient enters dental office and gives permission for non-invasive procedures such as consultation, examination and diagnosis, whereas expressed consent is a formal type of permission related to more invasive procedures. In dentistry, various forms of expressed consent i.e., verbal and written consent is used adequately for routine or complex dental treatment such as dental filling, cleaning of teeth, extraction, surgical procedures which requires sedation etc [9]. The process of informed consent starts with educating and discussing with the patient about the procedure and ends with documentation [10]. The document used by doctors and hospitals to obtain patient's legal consent - commonly referred to as the "informed consent form" must be in simple language, clear and understandable to the patients. It should be based on sufficient and accurate information about nature of treatment proposed, expected benefits, risks, complications and alternatives to the recommended treatment.

Proper documentation of the whole findings is very necessary as without it the whole process of obtaining informed consent will be worthless. This form is not only beneficial to patients but to doctors also as in current daily practice they are facing more cases of malpractice suits related to doctor-patient relationship or patient's confidentiality $[11,12]$. So, the use of informed consent prevents malpractices or quackery and failure to obtain informed consent is a departure from the standard of care $[13,14]$. One form of malpractice is defensive medicine in which doctor performs unnecessary treatment or diagnostic procedure just to protect himself/herself against litigation or malpractice claim cases. Hence, this study was designed to explore the knowledge, attitude and practice of ethics of informed consent among dental surgeons of Bangalore South.

\section{Materials and Methods}

Study Design: A cross sectional descriptive study was conducted among dental practitioners of Bangalore South to assess their knowledge, attitude and practices regarding patient's informed consent. The data was collected during the month of June -August 2015.

Study Population: Dental practitioners practising in South Bangalore city.

Ethical Approval: The study protocol was reviewed by the Ethical committee of Institutional Review Board and was granted ethical clearance.

Sample Size: Pilot study was conducted among 30 dental practitioners to determine the feasibility of the study and to calculate the sample size. Later on they were excluded from the main sample size. Based on the results of the pilot study, sample size was calculated.

Sample size was derived using the formula.

$$
\text { Sample Size }=\left\{Z^{2} *(p) *(q)\right\} / d^{2}
$$

Where $\mathrm{Z}=\mathrm{Z}$ value for the confidence level chosen $=1.96$ (for 95\% confidence level - from standard normal distribution)

$$
\begin{aligned}
& \mathrm{p}=\text { Proportion in the target population }(68 \%=0.68) \\
& \mathrm{q}=1-\mathrm{p}=1-0.68=0.32 \\
& \mathrm{~d}=\text { Margin of error which is acceptable }=10 \% \text { of } \mathrm{p}
\end{aligned}
$$$$
=10 \% \text { of } 0.68=0.068
$$$$
\text { Sample size }=(1.96) 2 \times 0.68 \times 0.32 /(0.068) 2
$$$$
=0.82 / 0.004=205
$$

Hence a sample size of 205 dental practitioners was taken for this study.

Methodology: Bangalore city was divided into four zones as North, South, East and West and in this study; private dental practitioners of south zone were selected randomly. The list of the dental surgeons practising in Bangalore South was obtained from the local Indian Dental Association (IDA) branch. Two hundred and five dentist of Bangalore South were selected randomly using that list. Self-administered questionnaire was distributed to all the respondents in their dental clinics and were asked to respond to this survey and to rate each item of the questionnaire choosing the most suitable response. They were informed about the study and their participation was purely voluntary.

Study Tool: The questionnaire consisted of previously validated 27 closed ended questions $[1,8,15,16]$. Demographic details of the private practitioner were collected regarding gender, qualification and practice experience. Questionnaire was designed to obtain dental practitioners knowledge, attitude and practices towards informed consent. Out of 27 questions, 07 questions were related to knowledge of practitioners, 14 were related to their attitude towards consent process and 06 were related to their dental practices. In the questionnaire, 03 questions were based on two-point likert scale, 13 questions were based on three-point scale, 02 questions were based on four-point likert scale.

Statistical Analysis: All completed questionnaires were coded and data entry was done in Microsoft Excel 2013. IBM SPSS Statistics V22.0 was used for descriptive data analysis; the results were then tabulated for calculation of response percentage.

\section{Results}

The present study was conducted on 205 dental practitioners of Bangalore South. Demographic data showed that majority of the respondents were males (60.5\%), had 6-10 years of dental practice $(34.6 \%)$ and had BDS degree (55.1\%) (Table 1 \& 2) showing the knowledge and awareness of dental practitioners related to consent and its procedures. Majority of the dentist had knowledge and awareness about informed consent (91\%), consumer protection act (80\%) but very few were aware about the proxy consent (51\%) and giving one copy of informed consent form to the patient $(22 \%)$. Most of the dentist felt that it is necessary to explain treatment plan before taking consent (89.7\%), consent 
process helps with the treatment $(74 \%)$ and patient consent is important in our profession (83\%). To know about the attitude of dental practitioners, they were asked about the type of consent obtained from illiterate patients, $46.4 \%$ answered verbal consent and thumbprint both should be taken followed by verbal consent only (34.2\%). Majority of the respondents thought that main area of consent should describe the risks or complications associated with the procedure $(64.4 \%)$ (Table 3 ).

Table 1: demographic characteristics of dentists $(n=205)$.

\begin{tabular}{|c|c|c|c|}
\hline \multicolumn{4}{|c|}{ Demographic Characteristics of Dentists $(n=205)$} \\
\hline Demographic characteristics & Frequency (n) & & Percentage (\%) \\
\hline Gender: Male & \multicolumn{2}{|c|}{124} & 60.5 \\
\hline Female & \multicolumn{2}{|c|}{81} & 39.5 \\
\hline \multicolumn{4}{|l|}{ Years Of Dental Practice } \\
\hline 5-Jan & \multicolumn{2}{|c|}{$\begin{array}{l}67 \\
71\end{array}$} & 32.6 \\
\hline 10-Jun & \multirow{2}{*}{\multicolumn{2}{|c|}{$\begin{array}{l}71 \\
54\end{array}$}} & 34.6 \\
\hline 20-Nov & & & 26.4 \\
\hline$>20$ & \multicolumn{2}{|c|}{13} & 6.4 \\
\hline Education Level of Dentist & Males & Females & \\
\hline BDS (113) & 54 & 59 & 55.1 \\
\hline MDS (92) & 70 & 22 & 44.9 \\
\hline
\end{tabular}

Table 2: Dental practitioner's knowledge and awareness about informed consent and its procedures

\begin{tabular}{|c|c|c|c|}
\hline \multicolumn{2}{|c|}{ Dental Practitioner's Knowledge And Awareness About Informed Consent And Its Procedures } \\
\hline Question & Yes & No & Not sure \\
\hline Knowledge about informed consent & $186(91 \%)$ & 0 & $19(9 \%)$ \\
\hline Knowledge about proxy consent & $105(51 \%)$ & $12(6 \%)$ & $56(27 \%)$ \\
\hline $\begin{array}{c}\text { Awareness about consumer } \\
\text { protection act }\end{array}$ & $164(80 \%)$ & $77(38 \%)$ & $83(40 \%)$ \\
\hline $\begin{array}{c}\text { Awareness about giving one copy } \\
\text { of the informed consent form to the } \\
\text { patient }\end{array}$ & $45(22 \%)$ & $02(1 \%)$ & $19(9.3 \%)$ \\
\hline $\begin{array}{c}\text { Necessity of explaining treatment } \\
\text { plan to the patient before taking } \\
\text { consent }\end{array}$ & $184(89.7 \%)$ & $04(2 \%)$ & $50(24 \%)$ \\
\hline $\begin{array}{c}\text { Consent process helps with the } \\
\text { treatment }\end{array}$ & $151(74 \%)$ & - & $35(17 \%)$ \\
\hline $\begin{array}{c}\text { Patient consent is important in our } \\
\text { profession }\end{array}$ & $170(83 \%)$ & & \\
\hline
\end{tabular}

Table 3: Attitude Of Dental Practitioners Towards Consent Process.

\section{Attitude Of Dental Practitioners Towards Consent Process}

\begin{tabular}{|c|c|}
\hline \multicolumn{2}{|l|}{ Main area of content in consent? } \\
\hline a) About the procedures & $70(34.1 \%)$ \\
\hline b) About risks/complications & $132(64.4 \%)$ \\
\hline c) Economic involvement & $00(0 \%)$ \\
\hline d) Long-time effects & $03(1.5 \%)$ \\
\hline \multicolumn{2}{|l|}{ Type of consent obtained from illiterate patients? } \\
\hline a) Verbal consent & $70(34.2 \%)$ \\
\hline b) Patient's thumbprint & $19(9.2 \%)$ \\
\hline c) Signature of relative & $21(10.2 \%)$ \\
\hline d) Verbal consent and thumbprint & $95(46.4 \%)$ \\
\hline From which patients, taking consent is not necessary? & $09(4.4 \%)$ \\
\hline a) Colleague & $30(14.6 \%)$ \\
\hline
\end{tabular}




\section{b) Relative}

c) Friend Long-time patient

d) None
$02(1 \%)$

$56(27.4 \%)$

$108(52.6 \%)$

Dental practitioners were asked about their practice regarding consent process. When asked about their routine habit of taking consent from patients in their clinical practice, 52\% of them responded that they took consent regularly from their patients, $9 \%$ agreed that they took consent from patient attenders also and $91.2 \%$ of the practitioners responded to taking consent from parents while treating their children. The dentists were asked if there were any cases in which they did not need to obtain informed consent. The respondents felt that there were some cases in which they did not obtain consent. These cases were supposed to be related to treatment of relative (14.6\%), Long-time patient $(27.4 \%)$, Colleague (4.4\%), Friend (1\%) and more than half $(52.6 \%)$ of the respondents replied that they should obtain informed consent from all the patients, no matter whom they treated. (Table 4) Dental practitioners were asked the form of informed consent they obtained in their clinical practice. Nearly half of the dentist (45\%) agreed that they obtained consent from the patient only in oral form, $15 \%$ in written form, 31\% in both oral and written forms and $9 \%$ of them did not take consent in any form (Figure 1).

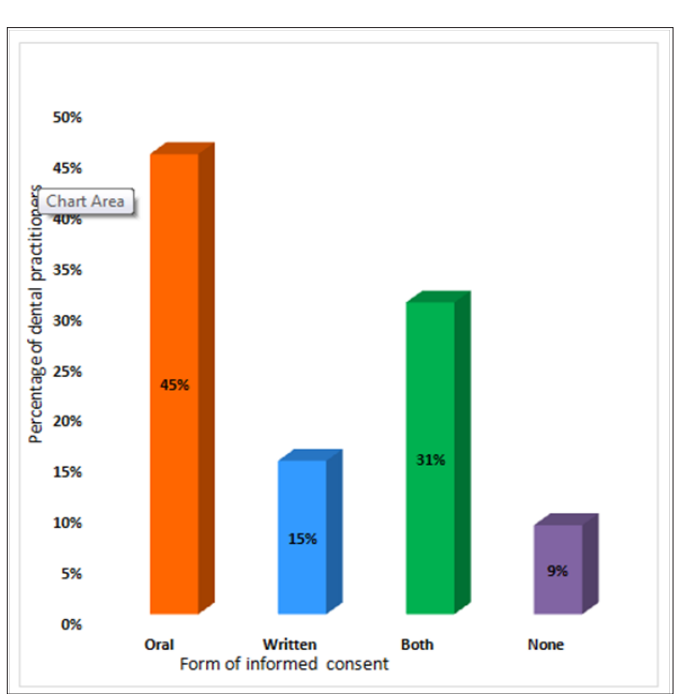

Figure 1: Form of the informed consent obtained in routine clinical practice.

Table 4: routine practice of dental practitioner's about consent and its procedures

\begin{tabular}{|c|c|c|c|}
\hline \multicolumn{3}{|c|}{ Routine Practice Of Dental Practitioner's About Consent And Its Procedures } \\
\hline Question & Yes & No & In definite cases \\
\hline $\begin{array}{c}\text { Taking informed consent from } \\
\text { patients }\end{array}$ & $107(52 \%)$ & $18(9 \%)$ & $80(39 \%)$ \\
\hline $\begin{array}{c}\text { Taking consent from patient } \\
\text { attenders }\end{array}$ & $18(9 \%)$ & $72(35 \%)$ & $115(56 \%)$ \\
\hline $\begin{array}{c}\text { Obtaining parent's informed } \\
\text { consent while treating their } \\
\text { children }\end{array}$ & $187(91.2 \%)$ & $1(0.5 \%)$ & $17(8.3 \%)$ \\
\hline
\end{tabular}

\section{Discussion}

Informed consent is an interactive process between doctor and patient, in which trust is the vital element. A cross-sectional descriptive study comprising of 27 previously validated questions was carried among dental practitioners of Bangalore South to assess their knowledge, attitude and practice towards informed consent In this study, the information obtained suggested that most dental practitioners appreciated the substantial value of informed consent and $91 \%$ of the participants regarded consent as an integral part of dentistry. Our results are in accordance with a study conducted in 2014 by Vivek et al. [15] which found that $97.4 \%$ of dentists knew about informed consent. Maximum studies have shown that awareness of the dentists regarding various ethical principles and informed consent have increased due to various factors like media, inclusion of this topic in the curriculum, increased consciousness of patients' physician relationship, the medico legal issues coming within the practice etc.

The responses for the question related to knowledge of proxy consent showed that $51 \%$ of the dentist knew about proxy consent and when asked about the situation where it is used, only $32.5 \%$ respondents believed that it could be used under 18 years of age. Proxy consent is used in situation in which patient is unable to give consent due to various reasons like either the person is minor or is mentally unsound/unconscious. In those conditions, a parent or any close relative can give consent on behalf of patient. Since the 1976 publication of an American Academy of Paediatrics (AAP) policy statement on the legal concept of informed consent in paediatric practice, the concept of taking consent from children has evolved [18]. As obtaining consent for the treatment of children is a difficult task, so a proper collaboration between dentists, patient and parents should occur to make a proper decision regarding the treatment. In such situations, parents should provide informed permission for diagnosis and treatment of children.

As it is a difficult task, dentists are aware of this fact as $91 \%$ of them in the study replied that they always took consent in case of children. This was in accordance with the studies conducted by Gupta V et al. [15] (80\%) and Avramova N et al. [1] (87.5\%). To know the attitude of dentists towards consent process, they were asked about the importance of obtaining informed consent in dentistry. In our study majority of them (83\%) considered taking 
informed consent as an important step before every procedure and none of them considered it as unimportant. The results of our study are same with the studies conducted by Avramova N et al. [1] which showed those $78(97.5 \%)$ practitioners and MAI Khan et al. [16] in which all $46(100 \%)$ dental practitioners considered it necessary to take informed consent. Nowadays, issues of informed consent are increasing in all the fields including dentistry. So, to avoid any unforeseen mishaps dentists have realized the importance to obtain informed consent prior to every procedure.

Nearly half of the respondents agreed that they used to record consent from patients only in verbal form in their clinical practice. Dentists should appreciate and follow the process of obtaining informed consent because it contributes to improved communication and rapport with the patients and contributes a lot to provide quality treatment and various studies have showed that verbal consent is the most favourite method of obtaining consent from the patients. This may be due to patient overload or lack of time. The dentists were asked about importance of explaining treatment plan and all the complications before taking the consent. About $89.7 \%$ dentists felt that it is necessary to explain treatment plan before taking consent in our study. This was in accordance with a study conducted by Kotrashetty V et al. [17] in which $93.1 \%$ dentists stated that it is necessary to explain various treatment modalities before taking the consent. Dentists should explain clearly about the pros and cons of a treatment, alternatives to the suggested treatment (including the option of no treatment), risks and benefits of the suggested treatment (and comparing them to the risks and benefits of alternatives). The patient and the dentist should openly discuss these options before the patient chooses the most suitable treatment of choice.

When asked about the most preferred method of taking consent from illiterate patients, $46.4 \%$ dentists reported that verbal consent and thumbprint both should be taken from illiterate patients while recording consent from them. For illiterate patients, written form of consent should be presented orally to the subject or in presence of one witness. In addition to the verbal consent, thumbprint or signature of a witness to the consent process and signature of the person conducting the consent interview must be taken for the purpose of documentation and a valid proof that the patients has clearly understood all the elements and details of the consent process. The dentist was asked about the awareness of giving one copy of the consent form if the patient asked for it. In the present study, 22\% of them were aware about giving one copy to the patient. The results of these studies showed that a very less number of dentists were aware about the law and basic medical ethics practice of giving one copy to the patient if asked for. This is an indicator that our formal education curriculum lacks the teaching of individual rights and ethics, thus this could be categorised as a simple case of ignorance of patients' rights. The dental practitioner should know that they should keep original form as a legal record that you agreed to the treatment and a copy of the consent form should be given to the patient.

The Consumer Protection Bill, 1986 was passed on 24th December, 1986 to protect interests of consumers in India [19]. The
Consumer Protection Act, 1986 is the first and the only act of its kind in India, which is established at the national, state and district level to increase consumer awareness and to protect their rights [20]. To know dental practitioners awareness towards this act, they were asked about it. The results of the study showed that about $80 \%$ respondents were aware about it. This was in accordance with a study conducted by Kotrashetty et al. [17], in which all 44 (100\%) dentists were aware about this act. But some studies showed contrary results with our study. One study showed that only $21.8 \%$ were aware about CPA [21]. The differences in results of the studies may be due to the fact that nowadays patients have become more aware of their rights and legislations and the increased sources of knowledge about the act.

\section{Limitations}

a) First of all, our study was a cross-sectional study with relatively small sample size and hence it was difficult to generalize the findings of the study. So, further study on the same topic is proposed with larger number of study subjects.

b) Our study involved dental practitioners of South Bangalore city only, which might not be representative of the dental practitioners of the whole Bangalore city.

c) Since it was a questionnaire study, respondents may read in a different way for each question and subsequently reply will be based on their own interpretation of the question, reflecting the inherent limitations of such studies as questionnaire based study cannot expose or truthfully predict the process of consent taking in real world situation.

\section{Conclusion}

In the present study, most dentists were aware of the importance of informed consent in dental practice, their duty towards patients but many were not using written consent as a routine procedure in their clinical practice. All of them were fully familiar about the informed consent process from children. Dentists should incorporate informed consent into their regular dental practice for all cases as it increases patient autonomy, trust and confidence as well as decreases malpractice.

Some of the recommendations are:

a) Awareness was high regarding the concept of informed consent but there are many gaps in the actual realization of its need, application and practice. Therefore regular workshops should be conducted to focus on this sensitive and important issue.

b) More stress should be given to training of undergraduate and postgraduate students on ethics and legal medicine as this is essential for dentists to protect themselves from any civil action and even from criminal process in case of any occurrence of mishaps.

\section{Clinical significance}

Despite its importance in medicine and dentistry, clinician ignores the value of taking proper informed consent from patients. 
Therefore there is an urgent need to give priority to this area by changing the attitude of the practitioners towards it, which in turn helps to avoid any unforeseen mishaps that can occur in the private practice and also will respect the patient autonomy ie, patient's right to decide what should be done with the one-self.

Acknowledgement: The authors would like to thank the participants of the study.

\section{References}

1. Avramova N, Yanev K (2011) Patients' Informed Consent in Dental Practice in Bulgaria. OHDM 10(2): 80-87.

2. (1996) International Conference on Harmonization of Technical Requirements for Registration of Pharmaceuticals for Human Use (ICH). Guideline for Good Clinical practice E6 (R1).

3. JE Samer (1985) Ethical problems facing the industry. Hosp Health Serv Admin 30(5): 44-45.

4. Mahmood K (2005) Informed consent and medical ethics. Ann King Edward Med Coll 11: 247-249.

5. Elnimeiri MKM (2008) Nuremberg code: A landmark document on medical research ethics. Sudanese J Public Health 3(2): 94-96.

6. Seldin LW (2003) Informed consent. The patient's rights. Dent Today 22(12): 86-88.

7. Katz RV, Kegeles SS, Kressin NR, et al. (2006) The Tuskegee legacy project: willingness of minorities to participate in biomedical research. J Health Care Poor Underserved 17(4): 698-715.

8. (2007) Dental Council of India. Bachelor of Dental Surgery Course Regulation 2007. New Delhi: Dental Council of India.

9. Tahir S, Ghafoor F, Nusarat S, Khan A (2009) Perception of consent among dental professionals. J Med Ethics Hist Med 20(2): 84-91.
10. Sterling VJ (1995) Informed consent. Patient education through the consent consultation. Oral Maxillofac Clin North Am 7: 665-670.

11. Jonsen AR (1998) the birth of the Bioethics. Oxford University Press, New York, USA.

12. Widdos H, Dickenson D, Hellsten S (2003) Global bioethics. New Rev Bioethics 1(1): 101-106.

13. Mohamed Tahir MA, Mason C, Hind V (2002) informed consent: optimism versus reality. Br Dent J 193(4): 221-224.

14. Bailey BL (1985) informed consent in dentistry. J Am Dent Assoc 110(5): 709-713.

15. Gupta V, Bhat N, Asawa K, Bapat M, Chaturvedi P (2015) Knowledge and Attitude Toward Informed Consent Among Private Dental Practitioners in Bathinda City, Punjab, India. Osong Public Health Res Perspect 6(2): 73-78.

16. MAI Khan, A Taleb (2012) Informed consent for dental treatment: A survey on Dental practitioner's perception, awareness, and understanding. Bangladesh Journal of Dental Research and Education 2(2): 31-35.

17. Kotrashetti V, Kale A, Hebbal M, Hallikeremath S (2010) Informed consent: a survey of general dental practitioners in Belgaum city. Indian Journal of Medical Ethics 7(2): 90-95.

18. (1976) American Academy of Pediatrics Task Force on Pediatric Research, Informed Consent, and Medical Ethics. Consent Pediatrics 57: 414-416.

19. (1987) The Consumer Protection Act, 1986 \& Rules.

20. Consumer Protection and National Consumer Disputes Redressal Commission. NCDRC.

21. Gambhir R, Dhaliwal J, Anand S, Bhardwaj A (2015) Knowledge and awareness of Consumer Protection Act among private dentists in Tricity, Punjab. J Family Med Prim Care 4(3): 347-351. 